Dicle Tıp Dergisi / Dicle Med J (2018) 45 (1) : 29 - 34

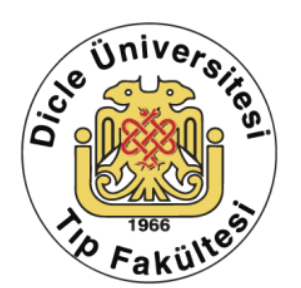

www.diclemedj.org

Özgün Araștırma / Original Article

\title{
İzole Tip 2 Slap Lezyonu Nedeniyle Artroskopik Tamir Uygulanan Hastaların Kısa Dönem Klinik Sonuçlarının Değerlendirilmesi
}

\author{
Baran Sarikaya1, Celal Bozkurt², Serkan Sipahioğlu3 \\ Pelin Zeynep Bekin Sarıaya4, Mehmet Akif Altay5 \\ 1 Harran Üniversitesi Tıp Fakültesi Ortopedi ve Travmatoloji Anabilim Dalı, Şanlıurfa, Türkiye ORCID: 0000-0002-9886-7221 \\ 2 Harran Üniversitesi Tıp Fakültesi Ortopedi ve Travmatoloji Anabilim Dalı, Şanlıurfa, Türkiye ORCID: 0000-0001-8747-1996 \\ 3 Harran Üniversitesi Tıp Fakültesi Ortopedi ve Travmatoloji Anabilim Dalı, Şanlıurfa, Türkiye ORCID: 0000-0002-2039-8189 \\ 4 Sarıkaya, Balıklıgöl Devlet Hastanesi, Radyoloji Kliniği, Şanlıurfa, Türkiye ORCID: 0000-0001-9588-6702 \\ 5 Harran Üniversitesi Tıp Fakültesi Ortopedi ve Travmatoloji Anabilim Dalı, Şanlıurfa, Türkiye ORCID: 0000-0001-9164-6090
}

Geliş: 09.06.2017, Revizyon: 20.09.2017, Kabul Tarihi: 05.10.2017

Özet

Amaç: Bu çalışmada, izole tip 2 süperior labrum anterior posterior (SLAP) lezyonu nedeniyle artroskopik SLAP tamiri uygulanan hastaların kısa dönem klinik sonuçlarının değerlendirilmesi amaçlandı.

Yöntemler: Konservatif tedaviye cevap vermeyen ve izole tip 2 SLAP lezyonu olan hastalar retrospektif olarak değerlendirildi. Hastalar klinik olarak Constant-Murley skorlama sistemi ve vizüel analog skala (VAS) sistemine göre değerlendirildi. Ameliyattan önce ve son takipte hastaların aktif ve pasif eklem hareket açıklıkları ölçüldü.

Bulgular: Toplam 19 hasta değerlendirildi. Hastaların 15'ierkek 4'ü ise kadındı. Ortalama yaş31.5(23-45)olarak tespit edildi. Ortalama takip süresi 16.8 ay (8-26) idi. Ameliyat öncesi Constant-Murley skorları ortalama57 (40-71)iken; son takipte ortalama 81 ( 66- 98) olarak saptandı. VAS değerleri ameliyat öncesi7 (6-9) iken; son takipte 2 (0- 5) olarak tespit edildi. Her iki skorlama sisteminde de ameliyat öncesi döneme klyasla son takiplerde istatistiksel olarak anlamlı değişiklikler saptandı $(\mathrm{p}<0.001)$.

Sonuç: İzole tip 2 SLAP lezyonu nedeniyle artroskopik SLAP tamiri uygulanan hastalarda, kısa dönemde klinik açıdan tatmin edici sonuçlar elde edilebilmektedir.

Anahtar kelimeler: Artroskopik, kısa dönem, cerrahi

DOI: $10.5798 /$ dicletip.363929

Yazışma Adresi / Correspondence: Baran Sarıkaya, Osman bey Kampusu, Ortopedi ve Travmatoloji Anabilim Dalı, Şanlıurfa-Mardin Karayolu Uzeri 18.Km, 63100, Şanlıurfa, Türkiye e-mail: baransarikaya@yahoo.com 


\title{
Evaluation of Short-term Clinical Results of the Arthroscopic Repair of Isolated Type 2 Slap Lesions
}

\begin{abstract}
Objective: The purpose of this study was to assess the clinical outcomes of isolated type II superior labrum anterior posterior (SLAP) lesions which were repaired arthroscopically

Methods: The patients who were underwent arthroscopic stabilization for isolated type IISLAP lesions were reviewed retrospectively. Shoulder function was evaluated according to the Constant-Murley score and visual analog scale (VAS) .Ranges of motion of the shoulders were evaluated both preoperatively and at the final follow-up.

Results: A total of19 patients were evaluated. Of the patients; 15 were male and 4 were female and 31.5(23-45) was determined to be the mean age. Mean follow-up duration was 16.8 months (8-26). Preoperative mean ConstantMurley score was57 (40-71), whereas it was determined to be a mean of 81 (66-98) at the final follow-up. VAS was determined to be 7(6-9) preoperatively, whereas it was determined to be 2 (0-5) at the final follow-up. Statistically significant differences were determined for both scoring systems at the final follow-up compared with the preoperative period $(\mathrm{p}<0.001)$.

Conclusion: Arthroscopic repair of isolated type II SLAP lesions appeared as a reliable and effective procedure with respect to short-time clinical outcomes.
\end{abstract}

Keywords: Arthroscopic, short-term, surgery

\section{GİRIŞ}

Biseps uzun başını içeren glenoidlabrum yırtıklarını ilk kez Andrew ve arkadaşları tanımlamışlardır1. Süperior labrumanterior posterior lezyonları (SLAP) ilk kez Snyder tarafından adlandırılmıştır ${ }^{2}$. Snyder, SLAP lezyonlarını dörde ayırmıştır, ancak yıllar geçtikçe SLAP lezyonları sinıflandırmasında artış saptanmıştır ${ }^{3}$. Tip 2 SLAP lezyonu süperior labrumunglenoide yapışma yerinden bisep stendonu ile birlikte ayrılmasıdır. Tip 1 SLAP lezyonunda labrumda dejenerasyon, tip 3 SLAP lezyonunda süperiorlabrumda kova sapı yırtık vardır. Tip 4 SLAP lezyonunda ise kova sapı yırtık bisep stendonuna ilerler. Bankard lezyonuna SLAP lezyonu eşlik ediyorsa tip 5 olarak adlandırılır. Glenoid bir saat kadranı olarak düşünüldüğünde, en sık SLAP lezyonları saat 11-13 arasında görülmektedir. SLAP lezyonları değerlendirilirken bisepsankorunun yapıştığ bölge, anterior-süperiorlabrum anatomik varyasyonları iyi bilinmelidir. Labrumun süperioru periferik olarak glenoide yapışırken santral kısmının tutunmadığı sublabralreses, kalın bir ortagleno humeral bağvarlığında anterior süperior labrumun olmaması (Buford kompleksi) bu varyasyonlardan başlıcalarıdır ${ }^{4} . \mathrm{Bu}$ tür anatomik varyasyonların klinik önemi, SLAP lezyonlarına yatkınlık oluşturabilmeleridir ${ }^{4}$.

SLAP lezyonları siklıkla atletlerde görülmektedir5. Baş üstü aktiviteler, tekrarlayan atma eylemi içeren aktiviteler ve abdüksiyonda kol üzerine düşme veyabu pozisyonda asılı kalma gibi hareketlerde SLAP lezyonları oluşabilir. Ağrı şikayeti ön plandadır. Kesin teşhisi koyduracak bir muayene testi olmamakla beraber aktif kompresyon testi (O'Brien) yüksek sensitiviteye sahiptir. SLAP lezyonları öncelikle konservatif tedavi ile tedavi edilir. Konservatif tedaviden fayda görmeyen hastalarda cerrahi tedavi planlanır. Cerrahi seçenekler; artroskopikdebridman, SLAP tamiri, tenotomi ve tenodez şeklindedir. Tenodez veya tenotomi ileri yaşlarda, bisep stendonunda dejenerayon-yırtık eşlik ediyorsa uygulanırken genç aktif hastalarda öncelikli cerrahi tedavi artroskopik SLAP tamiridir ${ }^{4}$.

$\mathrm{Bu}$ çalışmada izole tip 2 SLAP lezyonu olan hastaların artroskopik SLAP tamiri sonrasında erken dönemdeki klinik sonuçları değerlendirildi. 


\section{YÖNTEMLER}

İzole tip 2 SLAP lezyonu nedeniyle artroskopik SLAP tamiri uygulanan 19 hasta retrospektif olarak incelendi. Hastaların hepsinden ameliyat öncesi aydınlatılmış onam alındı. Hastalarda omuz ağrısı şikayeti ön plandaydı. Hastalar öncelikle konservatif tedaviye yönlendirildiler. Konservatif tedaviden fayda görmeyen ve düzenli olarak ameliyat öncesi ve sonrası takiplere gelen hastalar çalışma kapsamına alındılar. Bütün hastaların omuz direkt grafileri ve manyetik rezonans görüntüleri (MRG)değerlendirildi. Hastaların hiçbirisine artrografi uygulanmadı. Muayenede, bütün hastalara; biseps germe testi, kompresyon testi ve O'Brien (aktif kompresyon) testi SLAP lezyonlarını değerlendirmek için uygulandı. Konservatif tedaviden fayda görmeyen hastalarda SLAP teşhisi daha çok klinik olarak konuldu. MR görüntülerinin hepsinde SLAP teşhisi konulamadı. Hastaların ameliyat öncesi ve ameliyattan sonra omuz eklem hareketleri aktif ve pasif olarak ölçüldü. Hastaların ameliyat öncesi ve son takiplerdeki ConstantMurley skorları ile omuz ağrısı için vizüel analog skala (VAS) değerleri irdelendi.

\section{Cerrahi Teknik}

Hastalara genel anestezi altında lateraldekübit pozisyonda ameliyat edilecek olankola traksiyon uygulanarak omuz artroskopisi uyguland. Posterior portalden görüntü sağlandı. Anteriordan iki adetportal ile SLAP tamiri uygulandı. SLAP tamirleri için bir adet çift iplikli ankor kullanıldı. Bisep sankorunun önünden ve arkasından uygulanan dügümmler ile labrum tamir edildi (Șekil 1). Ameliyattan sonra velpo bandajı uygulandı. Hastalara ilk 15 gün pandüler egzersizler ve pasif omuz hareketleri uyguland. İkinci haftadan sonra aktif yardıml omuz eklem hareketleri uyguland. Birinci aydan sonra aktif hareketler verilere altıncı haftada bandaj sonlandırıldı.

\section{Istatistiksel Analiz}

İstatistiksel analizler için Windows için IBM SPSS 22.0 versiyonu (IBM Corporation, Armonk, NY, USA) kullanıldı. Verilerin dağılımı Kolmogorov-Smirnov testi ile değerlendirildi. Ameliyat öncesi ve sonrası Constant-Murley omuz skorları, VAS değerleri ve eklem hareket açlklık değerleri Wilcoxon signedrank testi ile değerlendirildi. İstatistiksel analiz sonucunda $\mathrm{p}$ değerinin < 0.05'ten küçük olması istatistiksel olarak anlamlı kabul edildi.

Tablo 1: Hastaların demografik özellikleri ve klinik skorlamaları

\begin{tabular}{|c|c|c|c|c|c|c|c|}
\hline \multicolumn{2}{|c|}{ Hasta } & \multirow{2}{*}{ Yaş (yıl) } & \multirow{2}{*}{ Takip Süresi (ay) } & \multirow{2}{*}{\multicolumn{2}{|c|}{ Constant-Murley Skoru }} & \multirow{2}{*}{\multicolumn{2}{|c|}{ Vizüel Analog Skala }} \\
\hline Erkek & Kadın & & & & & & \\
\hline \multirow{2}{*}{15} & \multirow{2}{*}{4} & \multirow{2}{*}{$31.5(23-45)$} & \multirow{2}{*}{$16.8(8-26)$} & Ameliyat Öncesi & Son Takip & Ameliyat Öncesi & Son Takip \\
\hline & & & & $57(40-71)$ & $81(66-98)$ & $7(6-9)$ & $2(0-5)$ \\
\hline
\end{tabular}

\section{BULGULAR}

Toplam 19 hasta çalışmaya dahil edildi. Hastaların 15'i erkek, 4' ü kadındı. Hastaların ortalama yaşı 31.5 (23-45)idi. Hastaların 7'si 40 yaş ve üzerindeydi. Ortalama takip süresi 16.8 ay (8-26) olarak tespit edildi. Ameliyata öncesi Constant-Murleyskorları ortalama 57 (40-71) iken ameliyat sonrası ortalama 81 (66-98) olarak saptandı. VAS değerleri ameliyat öncesi
7 (6-9) iken, ameliyat sonrası 2 (0-5) olarak tespit edildi. Hem Constant-Murley hem de VAS değerlerinde ameliyat öncesi döneme kıyasla ameliyat sonrası dönemde istatistiksel olarak anlamlı derecede değişiklikler tespit edildi $(\mathrm{p}<$ 0.001). Hastaların pasif eklem hareket açıklıklarında ameliyat öncesi ve son takipte herhangi bir kisitlılik yoktu. Aktif eklem hareketleri değerlendirildiğinde; fleksiyon 
ameliyat öncesi ortalama 150derece (130-180), son takipteise ortalama 160 derece (140-170), abdüksiyon ameliyat öncesi ortalama120 derece (110-140) iken son takipte ortalama130 derece (120-150) olarak saptandı. İç ve dış rotasyon omuz 90 derece abdüksiyondayken değerlendirildi. Ameliyat öncesi diş rotasyon ortalama 75 derece (60-90) son takipte ortalama 80 derece(70-90) olarak tepit edildi. Ameliyat öncesi ve son takiplerdeki eklem hareket açıklıkları arasında istatistiksel olarak anlamlı farklar yoktu.

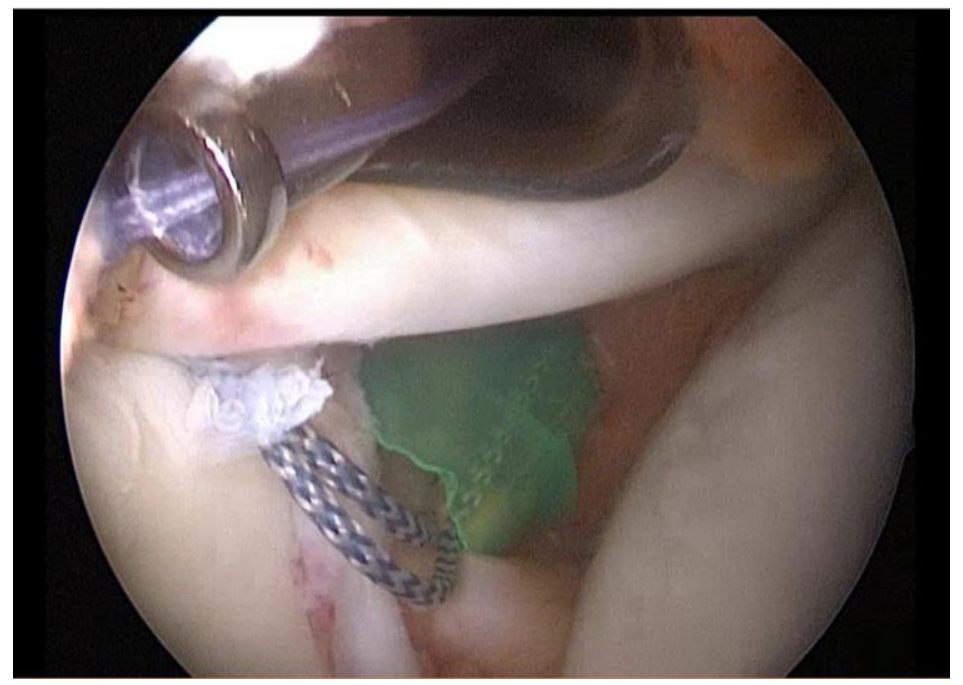

Şekil 1: Biseps tendonunun arkasından ve önünden uygulanan düğümler ile artroskopik SLAP tamiri.

\section{TARTIŞMA}

SLAP lezyonları sıklıkla diğer omuz patolojilerine eşlik eder. Snyder ve ark. yapmış oldukları bir çalışmada SLAP lezyonlarına eşlik eden en sık üç omuz patolojisi olarak; parsiyel rotator kaf yırtıkları (\%29), bankart lezyonları (\%22) ve tam kat rotator kaf yırtıklarını (\%11) belirlemişlerdir6. Görüldüğü üzere SLAP lezyonlarının yarıdan fazlası izole lezyon olmamaktadır. Bu çalışmadaki hasta grubu izole tip 2 SLAP lezyonu olan hasta grubunu içermektedir. Böylece diğer patolojiler olmadan, izole tamirin sonuçlarını daha net değerlendirme amaçlanmıştır.

SLAP teşhisi sıklıkla hikaye ve klinik şüpheyle konulur. Radyolojik olarak, MRG ile SLAP lezyonları her zaman tespit edilemeyebilir? SLAP lezyonlarını daha iyi değerlendirebilmek için girişimsel bir işlem olan MR artrografi uygulanabilir. Bencardino ve ark. yapmıș oldukları bir çalışmada MR artrografinin sensitivitesinin \%89, spesifitesinin ise $\% 91$ olduğunu göstermişlerdir ${ }^{8}$. $\mathrm{Bu}$ çalışmadaki hastalarda rutin olarak MRG tetkiki uygulandı ancak artrografi uygulanmadi. SLAP tanısı çoğu zaman MRGile konulamadı. Eklem içi sıvı artışı olan hastalarda SLAP teşhisi daha kolay konuldu. Eklem içerisindeki sıvı yırtık olan labrum ile glenoid arasina girerek MRG'de sinyal oluşturdu. SLAP lezyonlarında her nekadar MR artrografi yüksek sensitivite ve spesifiteye sahip olsa da; konservatif tedaviye cevap vermeyen ve klinik muayenede kapsülolabral patolojilerle ilgili şüphe uyandiran hastalarda, glenohumeral ve subakromial bölgeyi daha iyi değerlendirmek için, MR artrografi yerine tanısal artroskopi yapmak daha uygun olabilir. Artroskopi hem tanısal hem de tedavi amaçlı yapılan bir girişim olması, minimal invaziv cerrahi ile erken ișe ve spora dönüş sağlaması gibi nedenlerden dolayı avantajlı bir yöntemdir. 
SLAP lezyonlarının etiyolojisi ile ilgili yapılan çalışmalarda sebebin genellikle travmatik olduğu ortaya konulmuştur ${ }^{2,6,9}$. Bu çalışmadaki hastalar sorgulandığında, hastaların hikayesinde; travma, aşırıspor aktivitesi, zorlu çalışma koşulları ön plandadır. Literatür incelendiğinde genç hastalarda artroskopik tamir sonrası tatmin edici sonuçların elde edildiği gösterilmiştir. Ancak baş üstü aktiviteleri içeren profesyonel sporcularda sonuçlar her ne kadar iyi olsa da bu sporcularda yaralanma öncesiyle aynı performans kalitesi elde edilememiştir ${ }^{10,11}$. Bu çalışmadaki hasta grubunda baş üstü aktivasyonları içeren sporcu yoktu. Genç hastalar irdelendiğinde travma, spor yaralanmaları ve iş sırasında meydana gelen aşırı zorlamalar ve aşırı kullanım ön plandaydı. Kırk yaş üzerindeki hasta grubunda akut travmaya ve aşırı kullanıma bağlı omuz şikâyetleri olan hastalar bulunmaktaydı. Çalışmadaki hastaların Constant-Murley skorları ve VAS değerleri irdelendiğinde tatmin edici sonuçlar elde edilmiştir. Her iki klinik değerlendirme skorlaması literatürdeki diğer bazı çalışmalarla mukayese edildiğinde benzer sonuçlar vermektedirr2-15. $\mathrm{Bu}$ çalışmadaki klinik sonuçlar kırk yaş altı ve üstü hastalar şeklinde değerlendirildiğinde; aralarında herhangi bir farklılığın olmadığı tespit edilmiştir. Ancak hem takiplerin kısa dönem olması hem de kırk yaş üzeri hasta grubu sayısının fazla olmaması nedeniyle sağlıklı bir değerlendirme yapabilmek için daha uzun süreli takipler ve daha geniş hasta grubu gerekmektedir.

Orta yaş üstü hastalarda ( $>40$ yaş) SLAP tamirleri tartışmalıdır. Tedavi seçenekleri arasinda tenodez ve tenotomi bulunmaktadir. $\mathrm{Bu}$ yaş hasta grubunda izole SLAP lezyonu hastası oldukça azdır. Genellikle SLAP lezyonlarına rotatorkaf patolojileri veya diğer omuz lezyonları eşlik etmektedir. Orta yaş üstü hastalarda kaf patolojileri de eşlik ediyorsa veya bisep stendonunda dejenerasyon mevcutsa SLAP tamiri yerine tenotomi veya tenodez yapılmasının daha iyi bir seçenek olduğunu bildiren çalışmalar mevcuttur ${ }^{5-17}$. Bisep stenotomisi veya tenodezi SLAP temirlerinin başarısızlıkla sonuçlanmış hastaların revizyonunda da tercih edilen başlıca yöntemlerdir ${ }^{18}$. Bu çalışmada orta yaş üzeri diye tabir edilebilecek toplam yedi hasta bulunmaktaydı. Bu hastaları değerlendirirken bisep stendonunda dejenerasyon olup olmaması, hastanın aktif bir yaşam tarzının olup olmaması gibi faktörler ön plandaydı. Nitekim aktif, çalışan ve bisep stendonunda dejenerasyonu olmayan bu hastalara da tıpkı genç hastalarda olduğu gibi SLAP tamiri uyguland. Takipler sırasında, bu hastaların kısa dönem klinik sonuçlarıyla genç hastalar arasında herhangi bir fark tespit edilmedi. Ancak sonuçların daha tatmin edici olabilmesi için orta ve uzun dönem takiplere de ihtiyaç vardir. Literatür, tenodez ve tenotomiyi orta yaş üzeri hastalarda önermektedir Ayrıca, yeterli literatür bilgisi olmasa da genç elit atletlerde de SLAP lezyonlarının tedavisinde bisepstenodezinin uygulanmasının eski sportif performans seviyelerine dönüşte iyi sonuçlar verdiği belirtilmiştir ${ }^{5,11}$.

Sonuç olarak; SLAP lezyonu dışında başka bir omuz patolojisi olmayan, bisepstendonunda herhangi bir dejenerasyonu olmayan genç hastalar ile, aktif orta yaş grubu hastalarda artroskopik SLAP tamiri sonrasinda kısa vadede tatmin edici sonuçlar alınabilmektedir.

Çıkar Çatışması Beyanı: Yazarlar çıkar çatışması olmadığını bildirmişlerdir.

Finansal Destek: Bu çalışma her hangi bir fon tarafından desteklenmemiştir.

Declaration of Conflicting Interests: The authors declare that they have no conflict of interest.

Financial Disclosure: No financial support was received. 


\section{KAYNAKLAR}

1. Andrews JR, CarsonWG Jr, McLeod WD. Glenoid labrum tears related to the long head of the biceps. AmJ Sports Med. 1985;13:337-41.

2. Snyder SJ, Karzel RP, Del Pizzo W, Ferkel RD, Friedman MJ. SLAP lesions of theshoulder. Arthroscopy. 1990;6:274-9.

3. Kanatlı U, Kütük AT, Öztürk BY. SLAP Lezyonları. Omuz Hastalıkları ve Artroskopisi, 1.. baskı. İzmir: US Akademi Yayınları, 2017:541-54.

4. Kanatli U, Ozturk BY, Bolukbasi S. Anatomical variations of the anterosuperior labrum: prevalence and association with type II superior labrum anteriorposterior (SLAP) lesions. J Shoulder Elbow Surg. 2010;19:1199-203.

5. Brockmeyer M, Tompkins M, Kohn DM, Lorbach 0 . SLAP lesions: a treatmen talgorithm. Knee Surg Sports Traumatol Arthrosc. 2016;24:447-55.

6. Snyder SJ, Banas MP, Karzel RP. An analysis of 140 injuries to the superior glenoid labrum. J Shoulder Elbow Surg. 1995;4:243-8.

7. Green MR, Christensen KP. Magnetic resonance imaging of the glenoid labrum in anterior shoulder instability. Am J Sports Med. 1994;22:493-8.

8. Bencardino JT, Beltran J, Rosenberg ZS, et al. Superior labrumanterior-posterior lesions: diagnosis with MR arthrography of the shoulder. Radiology. 2000; 214: 267-71.

9. Jobe FW, Giangarra CE, Kvitne RS, Glousman RE. Anterior capsulolabral reconstruction of the shoulder in athletes in over hand sports. Am J Sports Med. 1991; 19: 428-34.

10. Neri BR, ElAttrache NS, Owsley KC, Mohr K, Yocum LA. Outcome of type II superiorlabral anterior posterior repairs in elite over head athletes: effect of concomitant partial thickness rotator cuff tears. Am J Sports Med. 2011: 39:114-20.
11. Boileau P, Parratte S, Chuinard C, et al. Arthroscopic treatment of isolated type II SLAP lesions: biceps tenodesis as an alternative to reinsertion. Am J Sports Med. 2009 37:929-36

12. Boileau P, Parratte S, Chuinard C, et al. Arthroscopic treatment of isolated type II SLAP lesions: biceps tenodesis as an alternative to reinsertion. Am J Sports Med. 2009; 37:929-36.

13. Galano GJ, Ahmad CS, Bigliani L, Levine W. Percutaneous SLAP lesion repair technique is an effective alternative to portal of Wilmington. Orthopedics. 2010 Nov2;33:803.

14. Kaisidis A, Pantos P, Heger H, Bochios D. Arthroscopic fixation of isolated type II SLAP lesions using a twoportal technique. Acta Orthop. Belg. 2011;77;160-6.

15. O’Brien SJ, Allen AA, Coleman SH, Drakos MC. The trans-rotator cuff approach to SLAP lesions: technical aspects for repair and a clinical follow-up of 31 patients at a minimum of 2 years. Arthroscopy. 2002;18:372-7.

16. Erickson J, Lavery K, Monica J, Gatt C, Dhawan A. Surgical treatment of symptomatic superior labrum anterior-posteriortears in patients older than 40 years: a systematic review. Am J Sports Med. 2015;43:127482.

17. Franceschi F, Longo UG, RuzziniL,et al. No advantages in repairing a type II superior labrum anterior and posterior (SLAP) lesion when associated with rotator cuff repair in patients over age 50: a randomized controlled trial. Am J Sports Med. 2008;36:247-53.

18. Virk MS, Tilton AK, Cole BJ. Biceps tenodesis and superior labrum anterior to posterior (SLAP) tears. Am J Orthop (Belle Mead NJ). 2015;44:491-4. 